\title{
Quantitative Application to a Polypill by the Development of Stability Indicating LC Method for the Simultaneous Estimation of Aspirin, Atorvastatin, Atenolol and Losartan Potassium
}

\author{
Satheesh K. Shetty ${ }^{1,5 *}$, Koduru V. Surendranath ${ }^{1}$, Pullapanthula Radhakrishnanand ${ }^{1}$, \\ Roshan M. Borkar ${ }^{2}$,Prashant S. Devrukhakar ${ }^{2}$, Johnson Jogul ${ }^{3}$, Upendra M. Tripathi ${ }^{4}$ \\ ${ }^{1}$ United States Pharmacopeia-India Private Limited, Research and Development Laboratory, ICICI Knowledge Park, \\ Turkapally, Shameerpet, Hyderabad, India \\ ${ }^{2}$ National Institute of Pharmaceutical education and Research (NIPER), Hyderabad, India \\ ${ }^{3}$ Department of Chemistry, St. Kittel Science College, Dharwad, India \\ ${ }^{4}$ Startech Labs private Limited, SMR Chambers Madinaguda, Hyderabad, India \\ ${ }^{5}$ Department of Chemistry, Jawaharlal Nehru Technological University, Kukatpally, Hyderabad, India \\ E-mail:skshetty69@rediffmail.com,sks@usp.org \\ Received May 21, 2010; revised July 10, 2010; accepted July 23, 2010
}

\begin{abstract}
Polypill is a fixed-dose combination (FDC) containing three or more drugs in a single pill with the intention of reducing the number of tablets or capsules that need to be taken. Developing a single analytical method for the estimation of individual drugs in a Polypill is very challenging, due to the formation of drug-drug and drug-excipients interaction impurities. Here an attempt was made to develop a new, sensitive, single stability-indicating HPLC method for the simultaneous quantitative determination of Aspirin (ASP) Atorvastatin (ATV), Atenolol (ATL) and Losartan potassium (LST) in a polypill form in the presence of degradation products. Efficient chromatographic separation was achieved on a $\mathrm{C} 18$ stationary phase with simple mobile phase combination of buffer and Acetonitrile. Buffer consists of $0.1 \%$ Orthophosphoric acid (pH 2.9), delivered in a gradient mode and quantitation was carried out using ultraviolet detection at $230 \mathrm{~nm}$ with a flow rate of $1.0 \mathrm{~mL} / \mathrm{min}$. The retention times of Atenolol, Aspirin, Losartan potassium, and Atorvastatin were 3.3, 7.6, 10.7 and $12.9 \mathrm{~min}$ respectively. The combination drug product are exposed to thermal, acid/base hydrolytic, humidity and oxidative stress conditions, and the stressed samples were analyzed by proposed method. The method was validated with respect to linearity; the method was linear in the range of 37.5 to 150.0 $\mu \mathrm{g} / \mathrm{mL}$ for ASP, 5.0 to $20.0 \mu \mathrm{g} / \mathrm{mL}$ for ATV and 25.0 to $100.0 \mu \mathrm{g} / \mathrm{mL}$ for ATL and LST. Acceptable precision and accuracy were obtained for concentrations over the standard curve ranges. The validated method was successfully applied to the analysis of Starpill tablets constituting all the four drugs; the percentage recoveries obtained were $99.60 \%$ for ASP, $99.30 \%$ for ATV, $99.41 \%$ for ATL and $99.62 \%$ for LST.
\end{abstract}

Keywords: Liquid Chromatography, Polypill, Aspirin, Atorvastatin, Atenolol and Losartan Potassium, Forced Degradation, Validation, Stability Indicating

\section{Introduction}

A Polypill concept to reduce CVD by more than $80 \%$ was firstly given by Wald and Law [1] and has been applied to pharmaceutical preparations [2-6]. Foreseeing the need of different analytical methods for estimation of ingredients of these pills, the ultimate goal of our work was to develop and validate a single high-performance liquid chroma- tography method selective for the four main components of tablets Starpill. Starpill is a fixed dose combination of Aspirin (ASP), Atorvastatin (ATV), Atenolol (ATL) and Losartan potassium (LST). Each trilayered tablet contains Aspirin $75 \mathrm{mg}$, Atorvastatin $10 \mathrm{mg}$, Atenolol $50 \mathrm{mg}$ and Losartan $50 \mathrm{mg}$. Aspirin (ASP), 2-acetoxybenzoic acid affects platelet aggregation by irreversibly inhibiting prostaglandin cyclooxygenase. This effect lasts for the 
life of the platelet and prevents the formation of the platelet aggregating factor thromboxane A2 [7-8]. Atorvastatin (ATV), (3R, 5R)-7-[2-(4-fluorophenyl)-3-phenyl -4-(phenylcarbamoyl)-5-(propan-2-yl)-1H-pyrrol-1-yl]-3, 5-dihydroxyheptanoic acid is a selective competitive inhibitor of 3-hydroxy-3-methyl-glutarylcoenzyme A (HMG$\mathrm{CoA}$ ) reductase enzyme. This enzyme catalyzes the conversion of HMG-CoA to mevalonate, an early and rate limiting step in the synthesis of cholesterol [9]. Atenolol (ATL), $(R S)-2-\{4$-[2-hydroxy-3-(propan-2-ylamino) propoxy]phenyl $\}$ acetamide is a beta1-selective (cardio selective) beta-adrenergic receptor blocking agent without membrane stabilizing or intrinsic sympathomimetic (partial agonist) activities. This preferential effect is not absolute, however, and at higher doses, Atenolol inhibits beta2-adrenoreceptors, chiefly located in the bronchial and vascular musculature [10-11]. Losartan (LST), 2-butyl4-chloro-1-\{[2'-(1H-tetrazol-5-yl)biphenyl-4-yl]methyl $\}-1$ $H$-imidazol-5-yl) methanol is an angiotensin II receptor (type AT1) antagonist. Losartan and its principal active metabolite block the vasoconstrictor and aldosteronesecreting effects of angiotensin II by selectively blocking the binding of angiotensin II to the AT 1 receptor found in many tissues, (e.g., vascular smooth muscle, adrenal gland). The active metabolite is 10 to 40 times more potent by weight than Losartan and appears to be a reversible, non-competitive inhibitor of the AT 1 receptor [1213].

Extensive literature survey did not reveal any simple, sensitive and stability indicating LC method for the simultaneous determination of all the four drugs as a fixed dose combination. Literature survey reveals that a variety of spectrophotometric and chromatographic methods, and a stability indicating LC method, has been reported for determination of ASP and ATV in pharmaceutical preparations in combination with other drugs [14-21]. Spectrophotometer and chromatographic methods have been reported for determination of ATL, in combination with other drugs, in bulk and pharmaceutical preparations [22-23].Also there are some papers for the estimation of LST individually and combination with other drugs [24-27].The present drug stability test guideline Q1A (R2) [28-29] issued by International Conference on Harmonization (ICH) suggests that stress studies should be carried out on a drug to establish its inherent stability characteristics, leading to separation of degradation products and hence supporting the suitability of the proposed analytical procedures.

In the present paper an attempt has been made to develop an accurate, rapid, specific and reproducible method for the estimation of Aspirin (ASP), Atorvastatin (ATV), Atenolol (ATL) and Losartan potassium (LST) in Starpill along with method validation as per ICH norms.

\section{Experimental}

\subsection{Chemicals}

Samples of Aspirin (ASP) Atorvastatin (ATV), Atenolol (ATL) and Losartan potassium (LST) were procured from USP India (P) limited, Hyderabad, India (Figure 1). Market samples of Starpill (Cipla Ltd Mumbai) tablets were purchased from the retail pharmacy. HPLC grade Acetonitrile, Analytical reagent grade Orthophosphoric acid purchased from Merck, Darmstadt, Germany. High purity water was prepared by using Millipore Milli-Q plus water purification system. The purity of the all drug substances and the chemicals used for the experiment were greater than $99.5 \%$ and the purity of the working standards used for the analysis was $99.9 \%$.

\subsection{Equipments}

The LC system, used for method development, forced degradation studies and method validation was Waters 2695 binary pump plus auto sampler and a 2996 photo diode array detector. The output signal was monitored and processed using Empower software on Pentium computer (Digital equipment Co). Photo stability studies were carried out in a photo stability chamber (Mack Pharmatech, Hyderabad, India). Thermal stability studies were performed in a dry air oven (Mack Pharmatech, Hyderabad, India).Accelerated stability studies were performed in a stability Chamber (Thermo Lab Mumbai).

\subsection{Chromatographic Conditions}

The chromatographic column used was Inertsil ODS C18 $(150 \times 4.6) \mathrm{mm}$ with $5 \mu \mathrm{m}$ particles. The mobile phase A consists of $0.1 \%$ Orthophosphoric acid adjusted to $\mathrm{pH} 2.9$ with triethylamine (TEA). The mobile phase B consists of Acetonitrile. Flow rate of the mobile phase was 1.0 $\mathrm{mL} / \mathrm{min}$. The HPLC gradient program was set as: (time (min)/\% solution B: 0/5, 10/60, 15/80, 17/60, 20/5, 25/5. The column temperature was maintained at $35^{\circ} \mathrm{C}$ and the detection was monitored at a wavelength of $230 \mathrm{~nm}$. The injection volume was $10 \mu \mathrm{L}$. Buffer: Acetonitrile 80:20; $(\mathrm{v} / v)$ was used as diluent.

\subsection{Preparation of Standard Solutions}

A stock solution of ASP, ATV, ATL, and LST standard and sample $(7.5 \mathrm{mg} / \mathrm{mL}$ of ASP, $1 \mathrm{mg} / \mathrm{mL}$ of ATV, 5.0 $\mathrm{mg} / \mathrm{mL}$ each of ATL and LST) were prepared in diluent. Working solutions $0.075 \mathrm{mg} / \mathrm{mL}$ of ASP, $0.01 \mathrm{mg} / \mathrm{mL}$ of ATV, $0.05 \mathrm{mg} / \mathrm{mL}$ each of ATL and LST were prepared from above stock solution in the diluent for assay determination. 


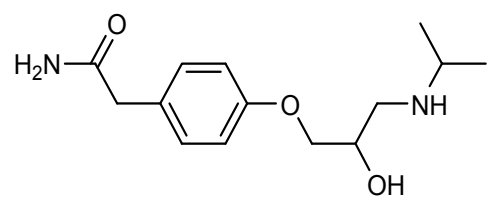

(a) Atenolol (ATL): (RS)-2-\{4-[2-hydroxy-3-(propan-2-ylamino)propoxy]phenyl ; acetamide, M.F: $\mathrm{C}_{14} \mathrm{H}_{22} \mathrm{~N}_{2} \mathrm{O}_{3}$, M.W: $266.336 \mathrm{~g} / \mathrm{mol}$.

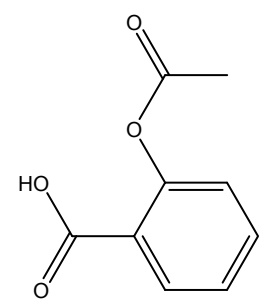

(b) Aspirin (ASP): 2-acetoxybenzoic acid, M.F: $\mathrm{C}_{9} \mathrm{H}_{8} \mathrm{O}_{4}$, M.W: 180.16 $\mathrm{g} / \mathrm{mol}$.

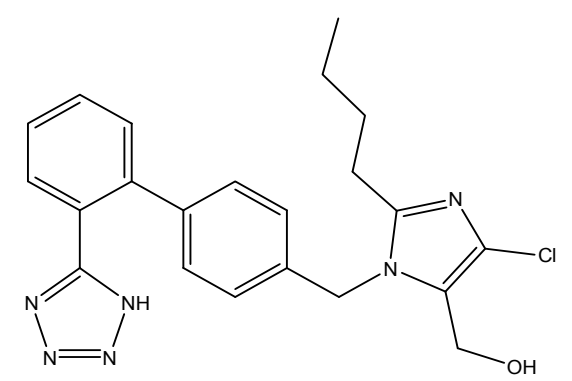

(c) Losartan (LST): 2-butyl-4-chloro-1-\{[2'-(1H-tetrazol-5-yl)biphenyl -4-yl]methyl \}-1H-imidazol-5-yl)methanol, M.F: $\mathrm{C}_{22} \mathrm{H}_{23} \mathrm{ClN}_{6} \mathrm{O}$, M.W: $422.91 \mathrm{~g} / \mathrm{mol}$.

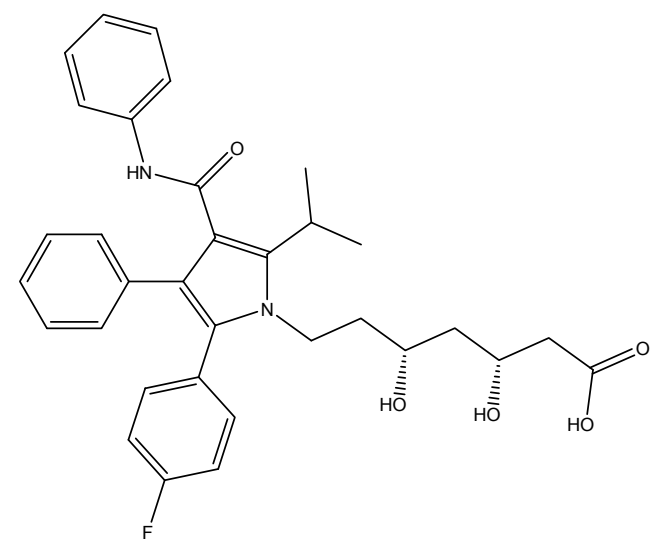

(d) Atorvastatin (ATV): (3R,5R)-7-[2-(4-fluorophenyl)-3-phenyl-4(phenylcabamoyl)-5-(propan-2-yl)-1H-pyrrol-1-yl]-3,5-dihydroxyheptanoic acid, M.F: $\mathrm{C}_{33} \mathrm{H}_{35} \mathrm{FN}_{2} \mathrm{O}_{5}$, M.W: $558.64 \mathrm{~g} / \mathrm{mol}$.

Figure 1. Chemical structures and labels of all the drug substances: ATL, ASP, LST and ATV.

\subsection{Preparation of Sample Solutions}

Twenty tablets were weighed and their average weight was calculated. The tablets were crushed to a homogeneous powder and a quantity equivalent to one tablet (75 mg ASP, $10 \mathrm{mg}$ ATV, $50 \mathrm{mg}$ : ATL and $50 \mathrm{mg}$ LST) was weighed in a $100-\mathrm{mL}$ volumetric flask, extracted in diluents by sonication, and filtered through Whatman no. 41 filter paper. The filtrate $(1 \mathrm{~mL})$ was quantitatively transferred to a $10-\mathrm{mL}$ volumetric flask, and solution was diluted to volume with the diluent.

\subsection{Preparation of System Suitability Solution}

System Suitability Solution was prepared by spiking 0.01 $\mathrm{mg} / \mathrm{mL}$ of Salicylic acid (SA) to a mixture of all the four drugs at the target test concentration levels $(0.075 \mathrm{mg} / \mathrm{mL}$ of ASP, $0.01 \mathrm{mg} / \mathrm{mL}$ of ATV, $0.05 \mathrm{mg} / \mathrm{mL}$ each of ATL and LST).

\subsection{Analytical Method Validation}

The developed chromatographic method was validated for selectivity, linearity, range, precision, accuracy, sensitivity, robustness and system suitability.

\subsubsection{Specificity/Application of Stress (Forced Degradation Study)}

Selectivity of the developed method was assessed by performing forced degradation studies. The terms selectivity and specificity are often used interchangeably. Specificity is the ability of the method to measure the analyte response in the presence of its potential impurities. Stress testing of the drug substance can help to identify the likely degradation products, which can in turn help to establish the degradation pathways and the intrinsic stability of the molecule and validate the stability indicating power of the analytical procedures used.

The specificity of the developed LC method for quantification of all the four drugs was determined in the presence of its degradation products. Forced degradation studies were performed on individual as well as mixture of all the four drugs, to provide an indication of stability indicating property and specificity of the proposed method [30-31].

The stress conditions employed for degradation study includes light (carried out as per ICH Q1B), heat $\left(60^{\circ} \mathrm{C}\right)$, acid hydrolysis $(0.1 \mathrm{~N} \mathrm{HCl})$, base hydrolysis $(0.1 \mathrm{~N} \mathrm{NaOH})$, water hydrolysis and oxidation $\left(5 \% \mathrm{H}_{2} \mathrm{O}_{2}\right)$. For acid study period was reflux for $1 \mathrm{~h}$, and oxidation it was at room temperature (RT) for $48 \mathrm{~h}$ and for base it was reflux for $2 \mathrm{~h}$. Peak purity of stressed samples was checked by using a 2996 photo diode array detector (PDA) from Waters. The purity angle within the purity threshold limit demonstrates the analyte peak homogeneity.

\subsubsection{Precision}

System Precision was investigated by injecting the 6 replicates of the sample preparations of the commercial tablet (Starpill).Repeatability (Intra-Day precision) of the assay method was evaluated by carrying out six inde- 
pendent assays of the commercial tablets $(0.075 \mathrm{mg} / \mathrm{mL}$ of ASP, $0.05 \mathrm{mg} / \mathrm{mL}$ of ATL and LST, $0.010 \mathrm{mg} / \mathrm{mL}$ of ATV test concentration) against qualified reference standard and calculating the \% RSD of the assay results.

Intermediate Precision (Inter-Day) was evaluated by carrying out the experiment with a different analyst, different column on different day and estimating the \% RSD of the result obtained.

\subsubsection{Sensitivity}

Sensitivity was determined by establishing the Limit of detection (LOD) and Limit of quantitation (LOQ) for ASP, ATV, ATL, and LST estimated at a signal-to-noise ratio of 3:1 and 10:1 respectively, by injecting a series of dilute solutions with known concentration. The precision study was also carried out at the LOQ level by injecting six individual preparations of ASP, ATV, ATL, and LST, calculated the $\%$ RSD for the areas of each drug.

\subsubsection{Linearity}

Linearity solutions were prepared from stock solution at five concentration levels from 50 to $200 \%$ of analyte concentrations (37.5 to $150 \mu \mathrm{g} / \mathrm{mL}$ for ASP, 5.0 to 20 $\mu \mathrm{g} / \mathrm{mL}$ for ATV and 25.0 to $100 \mu \mathrm{g} / \mathrm{ml}$ for ATL and LST). The peak area versus concentration data was collected and performed regression analysis by the method of least squares. The Correlation coefficient, Slope \& $y$-intercept values were calculated from the calibration plot obtained.

\subsubsection{Accuracy}

The accuracy of the method was determined by measuring the recovery of the drugs by the method of standard additions. Known amounts of each drug corresponding to 50,100 , and $150 \%$ of the target test concentrations $(0.075$ $\mathrm{mg} / \mathrm{mL}$ of ASP, $0.01 \mathrm{mg} / \mathrm{mL}$ of ATV, $0.05 \mathrm{mg} / \mathrm{mL}$ each of ATL and LST) were added to a placebo mixture to determine whether the exccipients present in the formulation led to positive or negative interferences. Each set of additions was repeated three times at each level. Extraction sample preparation procedure is followed and assayed against qualified reference standard. The accuracy was expressed as the percentage of the analytes recovered by the assay.

\subsubsection{Robustness}

To determine the robustness of the developed method, experimental conditions were deliberately changed and the relative standard deviation for replicate injections of ASP, ATV, ATL and LST peaks and the USP resolution factor between ASP and SA peaks were evaluated. The mobile phase flow rate was $1.0 \mathrm{~mL} / \mathrm{min}$. This was changed by 0.1 units to 1.1 and $1.2 \mathrm{~mL} / \mathrm{min}$. The effect of column temperature was studied at $40^{\circ} \mathrm{C}$ and $30^{\circ} \mathrm{C}$ instead of $35^{\circ} \mathrm{C}$. The effect of buffer $\mathrm{pH}$ was studied at $\mathrm{pH} 2.8$ and 3.0 .

\subsubsection{Solution Stability and Mobile Phase Stability}

The solution stability of ASP, ATV, ATL and LST was carried out by leaving the test solution in tightly capped volumetric flasks at room temperature for $48 \mathrm{~h}$ and assayed at $6 \mathrm{~h}$ interval, against the freshly prepared standard solution. The mobile phase stability was carried out by assaying the freshly prepared sample solution against the freshly prepared standard at $6 \mathrm{~h}$ interval up to $48 \mathrm{~h}$. The percentage of RSD of assay of ASP, ATV, ATL and LST was calculated for the study period during mobile phase and solution stability experiments.

\section{Results and Discussions}

\subsection{Method Development and Optimization}

All the four drug solutions were prepared in diluent at a concentration of $100 \mu \mathrm{g} / \mathrm{mL}$ and scanned in UV-Visible spectrometer; all the drugs were having UV maxima at around $230 \mathrm{~nm}$. Hence detection at $230 \mathrm{~nm}$ was selected for method development purpose.

The main analytical challenge during development of a new method was obtaining adequate retention of the polar parent compound, Atenolol (ATL) while maintaining a reasonable elution time for the less-polar Atorvastatin (ATV) and to separate one of the degradation impurity Salicylic acid (SA) from the ASP peak.

To achieve this, Water and Acetonitrile $(50: 50 \mathrm{v} / \mathrm{v})$ mobile phase, on a C18 stationary phase with a $25 \mathrm{~cm}$ length, $4.6 \mathrm{~mm}$ ID and $5 \mu \mathrm{m}$ particle size were investigated. Experiments were also performed using the columns of varying lengths from 250 to $100 \mathrm{~mm}$. Different mobile phase compositions containing phosphate buffer and Acetonitrile (50:50-20:80 v/v) were also tried. But was unsuccessful in getting good peak shapes for all the peaks. Although good separation was achieved with $0.1 \%$ phosphoric acid: Acetonitrile in the ratio of 50:50 (v/v), Atorvastatin peak symmetry was found to be greater than 2.0. The asymmetry of the Atorvastatin peak was improved by addition of Triethylamine (TEA) and adjusting the mobile phase $\mathrm{pH}$ to 2.9 in the aqueous phase. The chromatographic separation with better peak shape was achieved using a mixture of aqueous $0.1 \%$ Orthophosphoric acid and Acetonitrile in the ratio of 50:50 (v/v). The columns, 250, 150 and $125 \mathrm{~mm} \times 4.6 \mathrm{~mm}, 5 \mu \mathrm{m}$ of varied lengths were tried but $150 \times 4.6 \mathrm{~mm}, 5 \mu \mathrm{m} \mathrm{C} 18$ Column gave reasonable retention for all the peaks. But when degradation samples were injected with these conditions, one of the degradation impurity of ASP namely salicylic acid (SA) was not separated from the ASP Peak. Then method was optimized to separate all the degradants from the main peaks by changing to Gradient mode. Several gradient conditions were tried before optimizing the final gradient programme as: time ( $\mathrm{min}) / \%$ solution B: 0/5, 10/60, 15/80, 17/60, 20/5, 25/5 Effect of 
the diluent on the peak shapes was studied. The ATL peak was observed as split in most of the compositions of the buffer and Acetonitrile. Finally Buffer: Acetonitrile $(80: 20, \mathrm{v} / \mathrm{v})$ was optimized as the diluent to obtain good peak shapes.

The satisfactory chromatographic separation, with good peak shapes were achieved on Inertsil ODS-C18 $(150 \times 4.6) \mathrm{mm}$ with $5 \mu \mathrm{m}$ particles, using $0.1 \%$ Orthophosphoric acid (adjusted to $\mathrm{pH} 2.9$ with TEA) as mobile phase A and Acetonitrile as solution B with a flow rate of $1.0 \mathrm{~mL} / \mathrm{min}$. The HPLC gradient program was optimized as: (time $(\mathrm{min}) / \%$ solution B: 0/5, 10/60, $15 / 80,17 / 60,20 / 5,25 / 5$. The column temperature as maintained at $35^{\circ} \mathrm{C}$ and the detection was monitored at a wavelength of $230 \mathrm{~nm}$. The injection volume was 10 $\mu \mathrm{L}$. Buffer: Acetonitrile (80: 20, v/v) was used as diluent. In the optimized gradient conditions ATL, ASP, SA, LST and ATV were well separated with a resolution (Rs) of greater than 2 and the typical retention times of ATL, ASP, SA, LST and ATV were about 3.3, 7.6, 8.1, 10.7 and 12.9 respectively, the typical chromatogram of System suitability shown in Figure 2.

Peak purity of stressed samples of all the four drug substances were checked by using 2996 Photo diode array detector of Waters (PDA). The purity angle within the purity threshold limit obtained in all stressed samples demonstrates the analyte peak homogeneity. All stressed samples of the drug product (heat $\left(60^{\circ} \mathrm{C}\right)$, acid hydrolysis $(0.1 \mathrm{~N}$ $\mathrm{HCl})$, base hydrolysis $(0.1 \mathrm{~N} \mathrm{NaOH})$, water hydrolysis and oxidation (5\% H2O2)) were analyzed for extended run time of $60 \mathrm{~min}$ to check the late eluting degradants. The System suitability results were given in (Table 1).

The proposed method is applied for the assay analysis of 3 different batches of the polypills. The assay results obtained were within the specification limit. The assay of polypill is unaffected in the presence of excipients confirming the stability indicating power of the developed method.

\subsection{Method Validation}

\subsubsection{Precision}

The percentage RSD values for the assays in precision study were $0.4,0.8,0.4,0.5 \%$ (intra-day precision) and $0.5,0.8,0.6,0.7 \%$ (inter-day precision) for ASP, ATV, ATL, and LST confirming a good precision and the ruggedness of the method, The \% RSD obtained for the Ruggedness study were as shown in (Table 2).

\subsubsection{Sensitivity}

The limits of detection (LOD) and quantitation (LOQ) were established at signal-to-noise ratios of $3: 1$ and 10:1, respectively. The LOD and LOQ of ASP, ATV, ATL and LST were determined experimentally by injecting

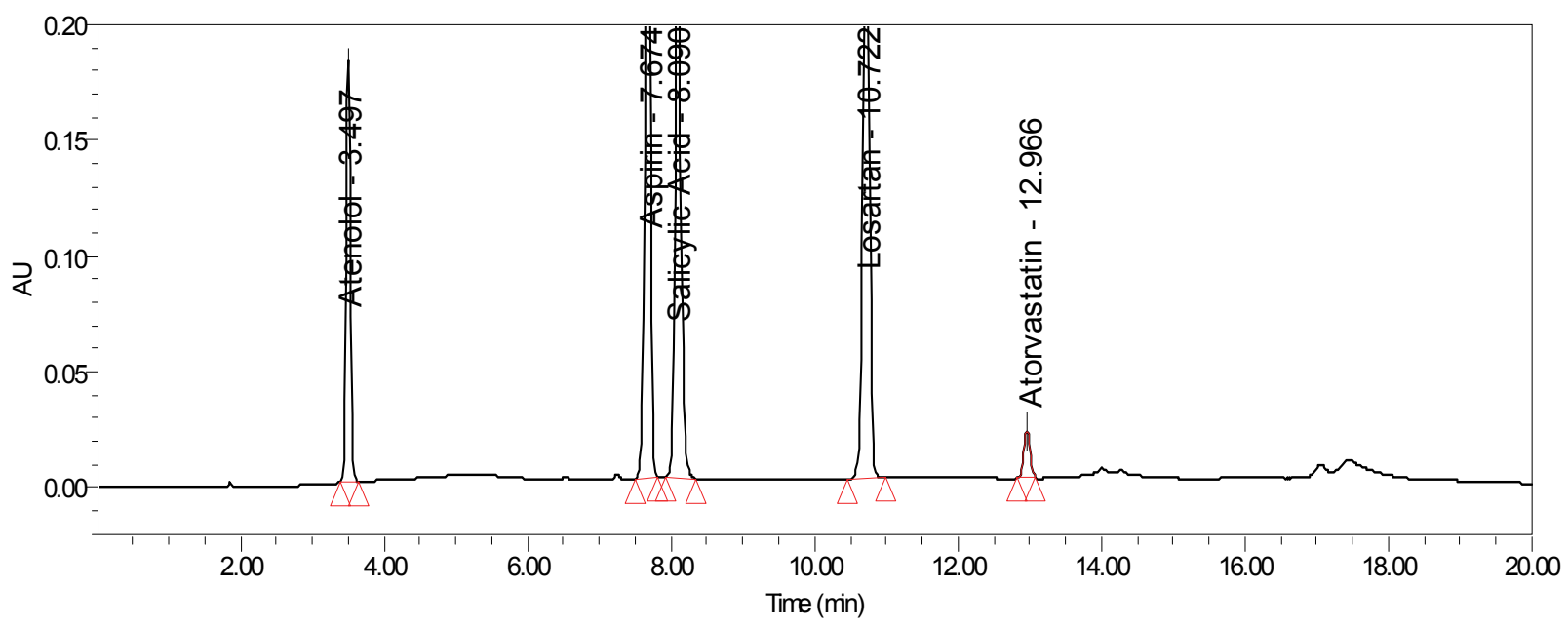

Figure 2. Typical chromatogram of system suitability.

Table 1. System suitability report.

\begin{tabular}{lcccc}
\hline \multicolumn{1}{c}{ Compound } & Retention time & $\begin{array}{c}\text { USP Resolution } \\
(\mathrm{RS})\end{array}$ & $\begin{array}{c}\text { USP Tailing factor } \\
(\mathrm{T})\end{array}$ & $\begin{array}{c}\text { No of theoretical plates USP } \\
\text { tangent method (N) }\end{array}$ \\
\hline Atenolol (ATL) & 3.5 & & 1.03 & 16743 \\
Aspirin (ASP) & 7.6 & 34.1 & 1.02 & 53435 \\
Salicylic acid (SA) & 8.1 & 2.8 & 1.1 & 46436 \\
Losartan (LST) & 10.7 & 16.6 & 0.99 & 76004 \\
Atorvastatin (ATV) & 12,9 & 13.4 & 0.97 & 91198 \\
\hline
\end{tabular}


Table 2. Results of intermediate precision.

\begin{tabular}{|c|c|c|c|c|c|c|}
\hline \multirow[t]{2}{*}{ S. No } & \multirow[t]{2}{*}{ Parameter } & \multirow[t]{2}{*}{ Variation } & \multicolumn{4}{|c|}{$\%$ RSD for Assay } \\
\hline & & & ASP & ATV & ATL & LST \\
\hline \multirow{2}{*}{1} & & (a) Waters 2695 Alliance system & $0.7 \%$ & $0.3 \%$ & $0.5 \%$ & $0.7 \%$ \\
\hline & & (b) Agilent 1100 series VWD system & $0.6 \%$ & $0.8 \%$ & $0.6 \%$ & $0.9 \%$ \\
\hline 2 & Different Column & (b)B.No:00118 & $0.5 \%$ & $0.4 \%$ & $0.6 \%$ & $0.6 \%$ \\
\hline \multirow{2}{*}{3} & & (a) Analyst-1 & $0.5 \%$ & $0.9 \%$ & $0.6 \%$ & $0.6 \%$ \\
\hline & Dintertit Amaryst & (b) Analyst-2 & $0.4 \%$ & $0.7 \%$ & $0.6 \%$ & $0.8 \%$ \\
\hline \multirow{2}{*}{4} & & (a) Day-1 & $0.4 \%$ & $0.9 \%$ & $0.3 \%$ & $0.5 \%$ \\
\hline & & (c) Day-3 & $0.6 \%$ & $0.7 \%$ & $0.4 \%$ & $0.4 \%$ \\
\hline
\end{tabular}

each drug six times. The LOD for ASP, ATV, ATL and LST were $0.1,0.2,0.15$ and $0.02 \mu \mathrm{g} / \mathrm{mL}$ respectively. The LOQ for ASP, ATV, ATL and LST were 0.3, 0.7, 0.4 and $0.06 \mu \mathrm{g} / \mathrm{mL}$, respectively.

\subsubsection{Linearity}

The linear ranges were from ( 37.5 to $150 \mu \mathrm{g} / \mathrm{mL}$ for ASP, 5.0 to $20 \mu \mathrm{g} / \mathrm{mL}$ for ATV and 25.0 to $100 \mu \mathrm{g} / \mathrm{mL}$ for ATL and LST).The correlation coefficient obtained was greater than 0.999. The Slope and the Intercept value obtained from the linear regression graph is as shown in (Table 3). The result shows an excellent correlation existed between the peak area and concentration of the analyte in the range $50-200 \%$ of analyte concentration.

\subsubsection{Accuracy}

The percentage recovery of the results obtained is listed in Table 4, the results indicate the method enables highly accurate simultaneous determination of the all the four drugs in the polypill combination.

\subsubsection{Robustness}

Close observation of analysis results for deliberately changed chromatographic conditions (flow rate, column temperature and $\mathrm{pH}$ of the mobile phase) revealed that the resolution between closely eluting peaks, namely ASP and SA was always greater than 2.0 and also there was not much effect on the peak shapes, illustrating the robustness of the method (Table 5).

\subsubsection{Solution Stability and Mobile Phase Stability}

The $\%$ RSD of assay of Polypill during solution stability and mobile phase stability experiments was within 1.0. No significant changes were observed in the content of ATL, ASP, LST and ATV during the study. The solution stability and mobile phase stability experiments data confirms that sample solutions and mobile phase used during assay determination were stable up to the study period of $48 \mathrm{~h}$.

Table 3. Results of Linearity study for drug substance.

\begin{tabular}{lcccc}
\hline & Atenolol (ATL) & Aspirin (ASP) & Losartan (LST) & Atorvastatin (ATV) \\
\hline Calibration Equation & Y=8027X-28993 & Y=18480X-65531 & Y=17299X-38592 & Y=1584X-6390 \\
Linearity Range & $50-200 \%$ & $50-200 \%$ & $50-200 \%$ & $50-200 \%$ \\
Regression coefficient & 0.999 & 0.999 & 0.999 & 0.999 \\
Slope & 8027 & 18480 & 17299 & 1584 \\
Intercept & -28993 & -65531 & -38592 & -6390 \\
\hline
\end{tabular}


Table 4. Results of accuracy study for drug substance.

\begin{tabular}{|c|c|c|c|c|c|}
\hline Analyte & Initial & Added & Concentration & RSD & Recovery \\
\hline & concentration $(\%)$ & concentration (mg) & found (mg) & $(\%)$ & $(\%)$ \\
\hline \multirow[t]{3}{*}{ Atenolol (ATL) } & 50 & 24.9 & 24.8 & 0.23 & 99.60 \\
\hline & 100 & 50.1 & 49.8 & 0.28 & 99.41 \\
\hline & 150 & 74.8 & 74.9 & 0.22 & 100.13 \\
\hline \multirow[t]{4}{*}{ Aspirin(ASP) } & 0 & 0 & 0 & & \\
\hline & 50 & 37.4 & 37.2 & 0.36 & 99.46 \\
\hline & 100 & 75.1 & 74.8 & 0.29 & 99.60 \\
\hline & 150 & 112.3 & 112.1 & 0.37 & 99.82 \\
\hline \multirow[t]{4}{*}{ Losartan(LST) } & 0 & 0 & 0 & & \\
\hline & 50 & 25.2 & 25.1 & 0.40 & 99.60 \\
\hline & 100 & 50.1 & 49.9 & 0.38 & 99.62 \\
\hline & 150 & 74.8 & 74.9 & 0.34 & 100.13 \\
\hline \multirow[t]{4}{*}{ Atorvastatin(ATV) } & 0 & 0 & 0 & & \\
\hline & 50 & 5.02 & 5.05 & 0.40 & 100.60 \\
\hline & 100 & 10.05 & 9.98 & 0.28 & 99.30 \\
\hline & 150 & 14.85 & 14.89 & 0.18 & 100.27 \\
\hline
\end{tabular}

Table 5. Results of robustness study.

\begin{tabular}{|c|c|c|c|}
\hline S.No & Parameter & Variation & $\begin{array}{l}\text { Resolution (Rs) } \\
\text { between ASP } \\
\text { and salicylic acid }\end{array}$ \\
\hline 1 & $\begin{array}{l}\text { Temperature }( \pm \\
5^{\circ} \mathrm{C} \text { of set } \\
\text { temperature) }\end{array}$ & $\begin{array}{l}\text { (a) At } 30^{\circ} \mathrm{C} \\
\text { (b) At } 40^{\circ} \mathrm{C}\end{array}$ & $\begin{array}{l}2.9 \\
2.7\end{array}$ \\
\hline 2 & $\begin{array}{l}\text { Flow rate }( \pm \\
20 \% \text { of the set } \\
\text { flow) }\end{array}$ & $\begin{array}{l}\text { (a) At } \\
0.8 \mathrm{~mL} \text { min-1 } \\
\text { (b) At } \\
1.2 \mathrm{~mL} \text { min-1 }\end{array}$ & $\begin{array}{l}2.9 \\
2.8\end{array}$ \\
\hline 3 & pH Buffer & $\begin{array}{l}\text { pH } 2.8 \\
\text { pH } 3.0\end{array}$ & $\begin{array}{l}2.9 \\
2.5\end{array}$ \\
\hline
\end{tabular}

\subsubsection{Results of Forced Degradation Studies}

1) Degradation Behavior

Stress studies on combination of all the four drugs under different stress conditions suggested the following degradation behavior.

2) Degradation in Acidic solution

The combination of all the four drugs was exposed to $0.1 \mathrm{~N} \mathrm{HCl}$ at $100^{\circ} \mathrm{C}$ for $1 \mathrm{~h}$. ATL, ASP and ATV showed considerable degradation. The drugs gradually undergone degradation with time in $0.1 \mathrm{~N} \mathrm{HCl}$ and prominent degradation was observed (Figure 3(a)).

3) Degradation in Basic solution

The combination of all the four drugs was exposed to $0.1 \mathrm{~N} \mathrm{NaOH}$ under reflux for $2 \mathrm{~h}$. ASP and ATV has shown significant sensitivity towards the treatment of 0.1 $\mathrm{N} \mathrm{NaOH}$. The drug undergone degradation immediately in $0.1 \mathrm{~N} \mathrm{NaOH}$ and prominent degradation was observed for ASP with the conversion to SA (Figure 3(b)).

4) Oxidative Conditions

The combination of all the four drugs was exposed to
$5 \%$ hydrogen peroxide at room temperature for $48 \mathrm{~h}$. ASP, LST and ATV has shown significant sensitivity towards the treatment of $5 \%$ hydrogen peroxide and the drugs gradually undergone oxidative degradation with time to yield prominent degradation products (Figure 3(c)).

5) Photolytic Conditions

When the combination of all the four drugs was exposed to light for an overall illumination of 1.2 million lux hours and an integrated near ultraviolet energy of 200-watt hours/square meter (w/mhr) (in photo stability chamber). Major degradation observed with LST and ATV (Figure 3(d)).

6) Thermal Degradation

When the drug product was exposed to dry heat at $60^{\circ} \mathrm{C}$ for $8 \mathrm{~h}$, Considerable degradation was observed with ATL and ASP (Figure 3(e)).

Accelerated Stability sample:

The stability indicating nature of the method was further confirmed by injecting three month accelerated stability sample and observed that all the degradants were well separated from the main components (Figure 3(f)).

Peak purity test results derived from PDA detector, confirmed that the all the four drug components were homogeneous and pure in all the analyzed stress samples. No degradants were observed after $30 \mathrm{~min}$ in the extended runtime of $60 \mathrm{~min}$ of all the samples.

6) Assay analysis

Assay analysis was performed for different batches of the drug product in tablets $(n=3)$, with the targeted analyte concentrations. The assay results obtained for the three Starpill tablets were, STP/002 (99.7\% ATL, 99.8\% ASP, 100.25 LST and $99.6 \%$ ATV), STP/005 (99.67\% ATL, $100.3 \%$ ASP, $99.4 \%$ LST and $99.8 \%$ ATV) and STP/011 (100.1\% ATL, 99.9\% ASP, 99.7\% LST and $100.3 \%$ ATV) depicted in (Table 6). 


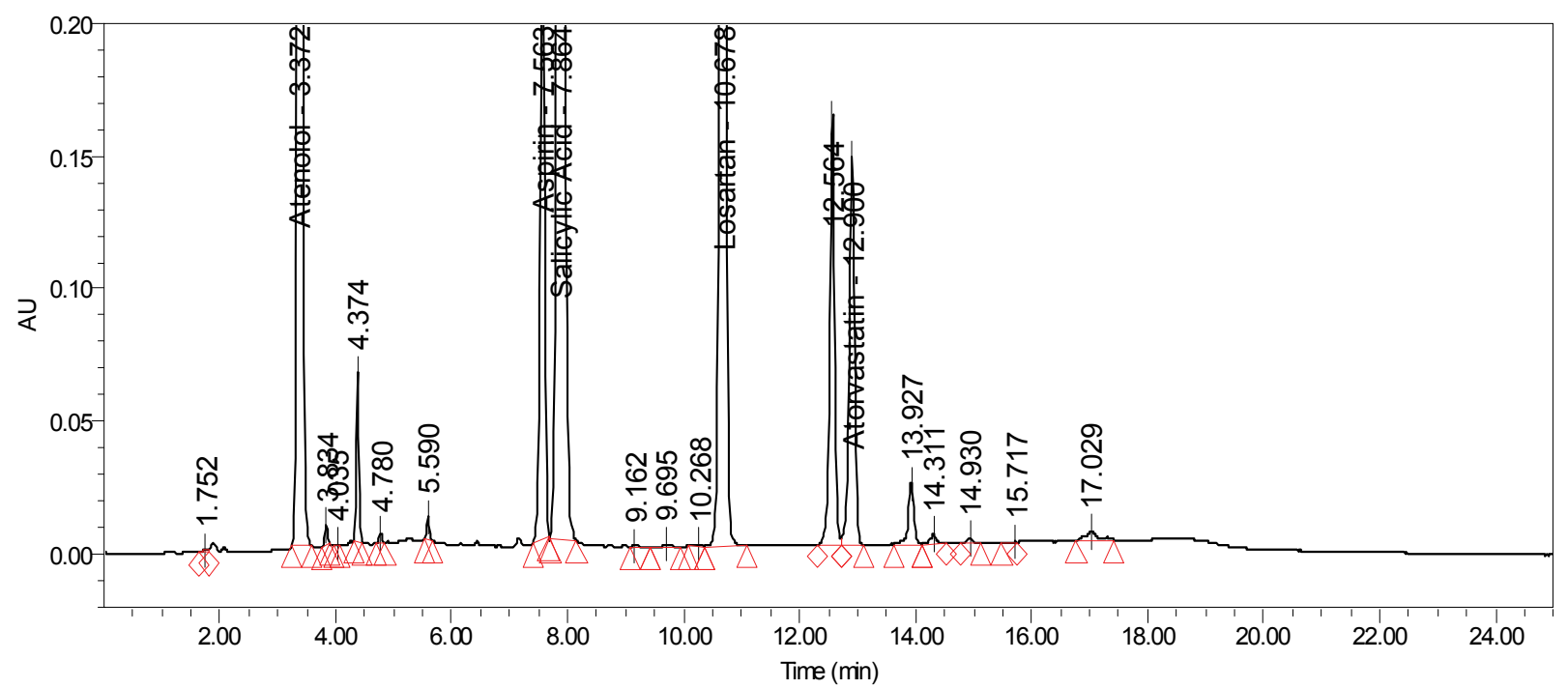

(a)

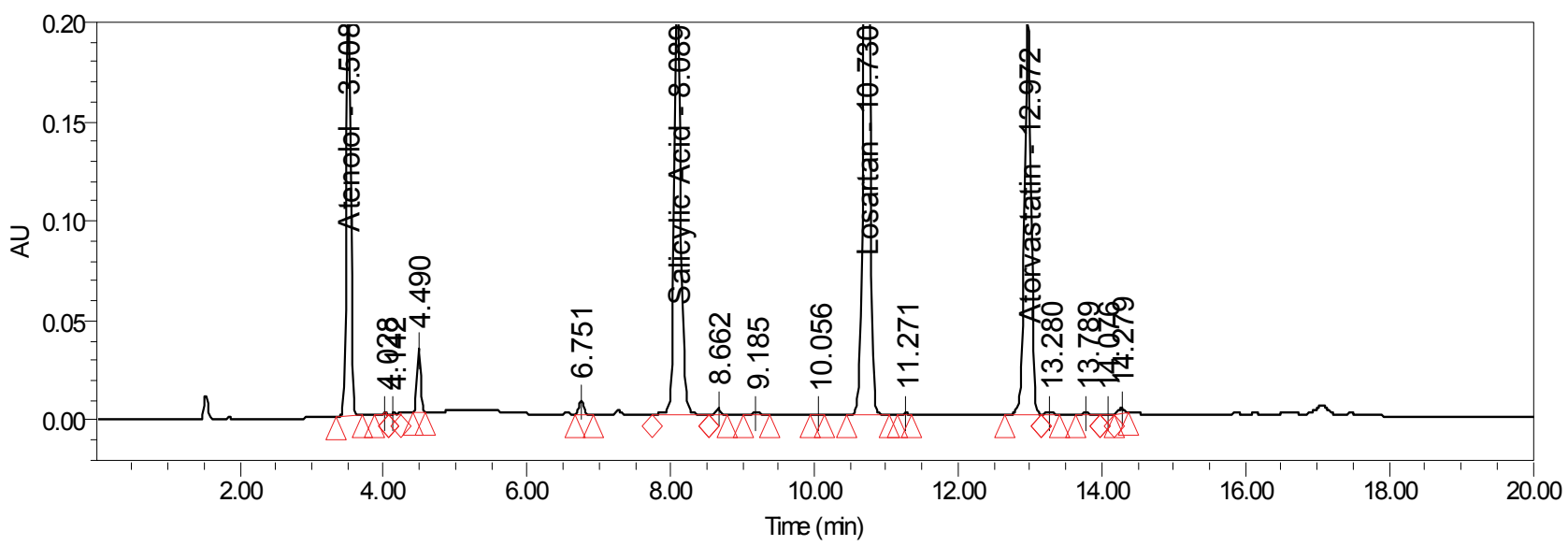

(b)

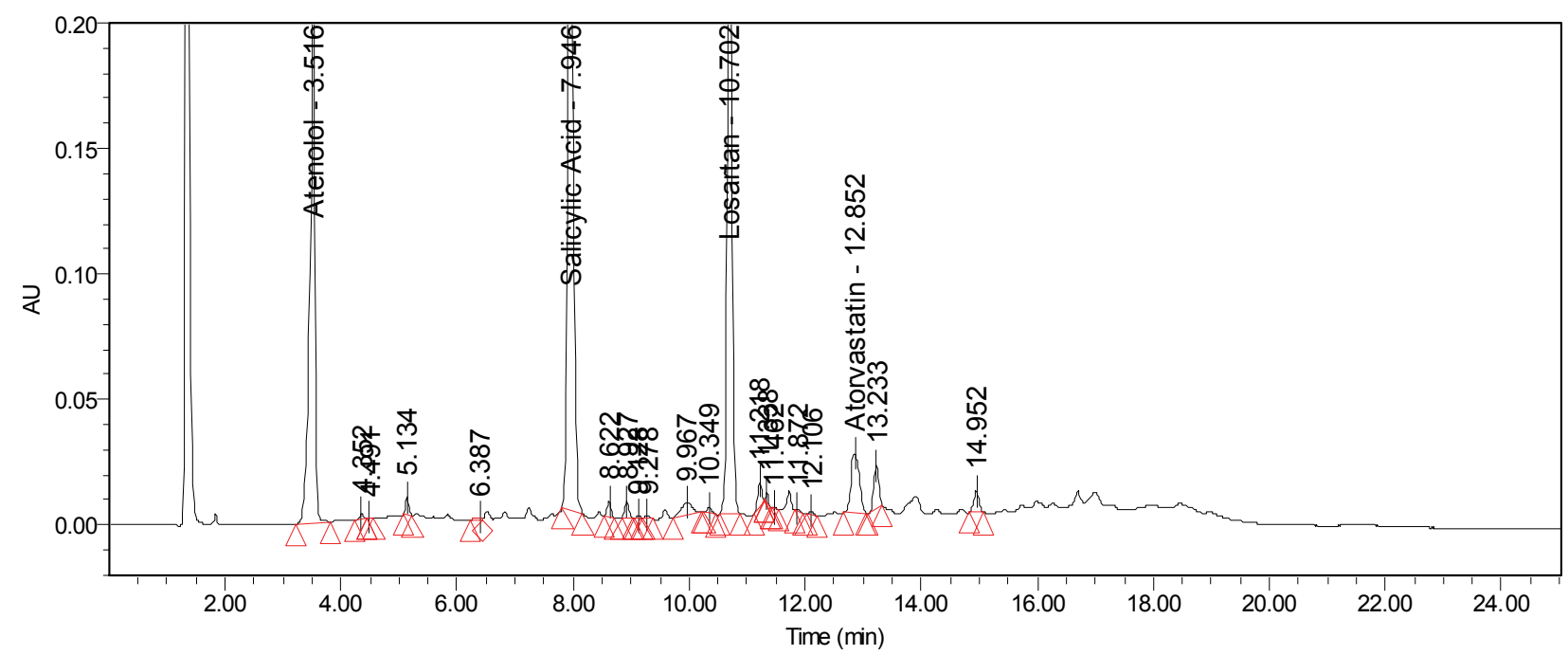

(c) 


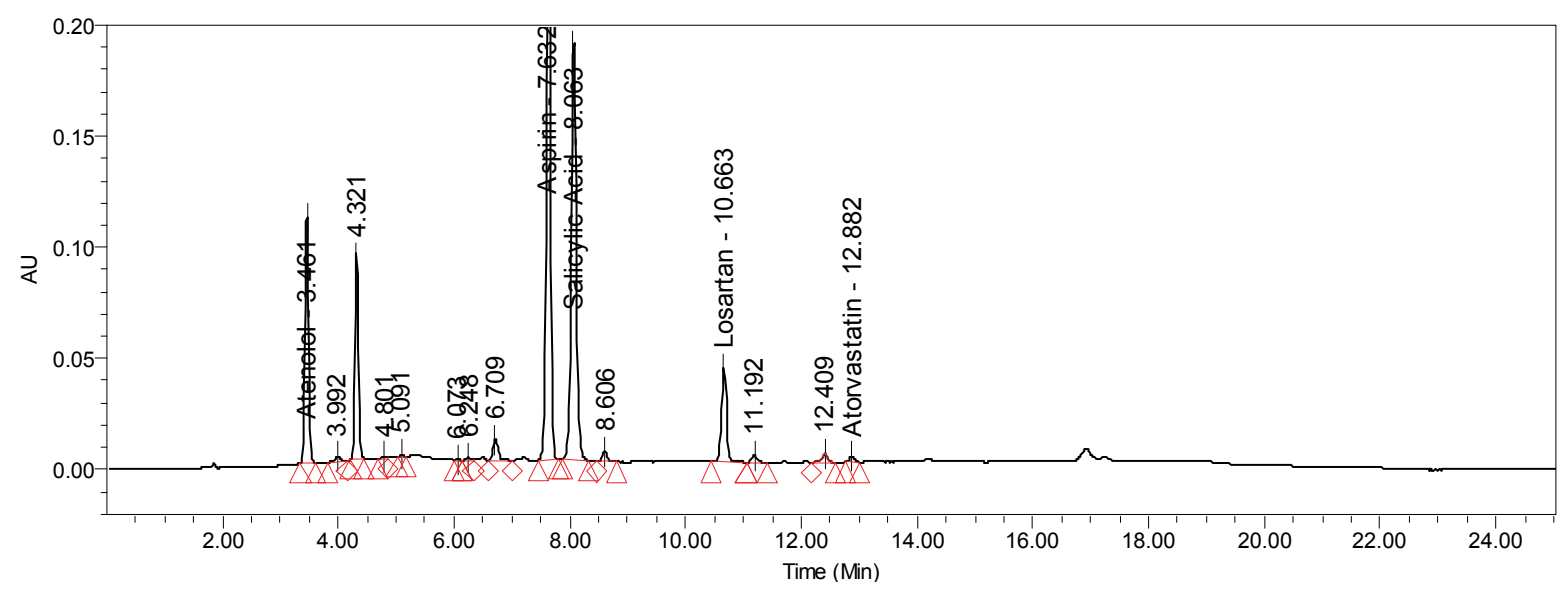

(d)

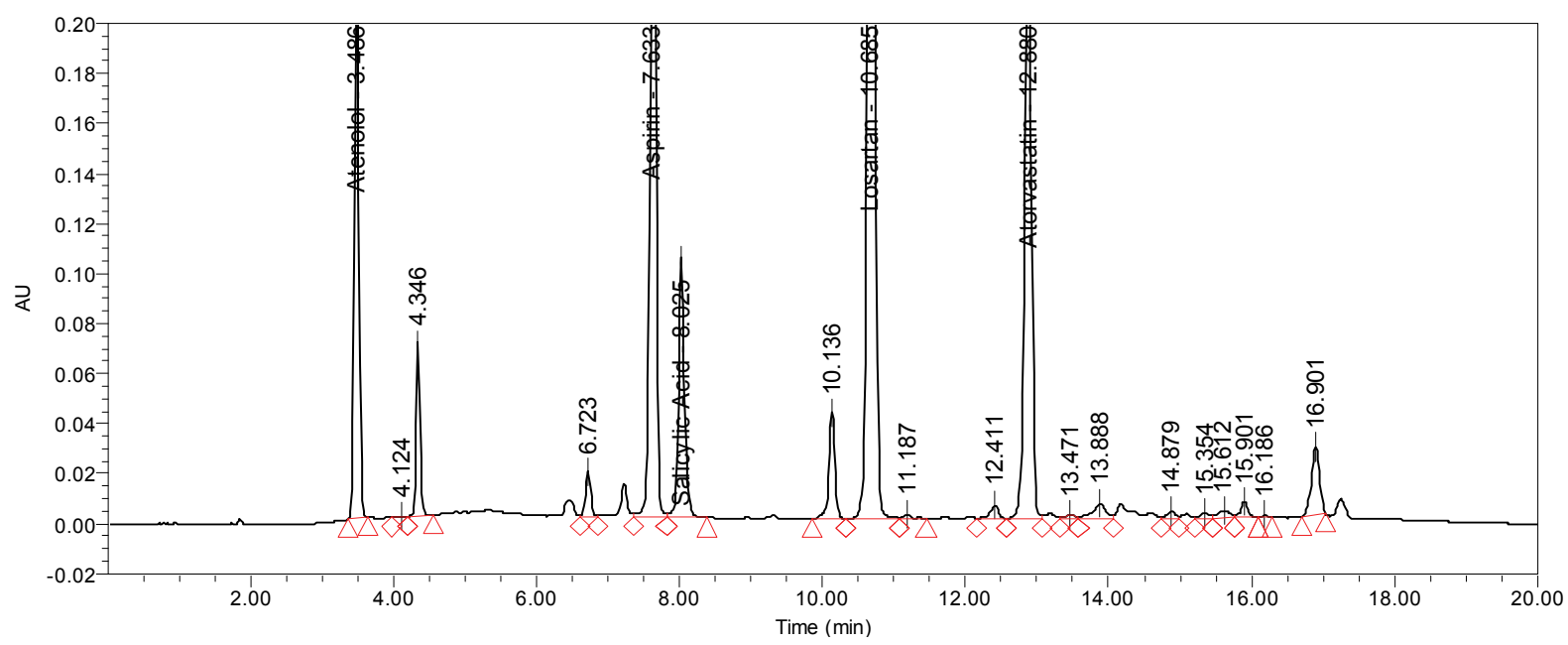

(e)

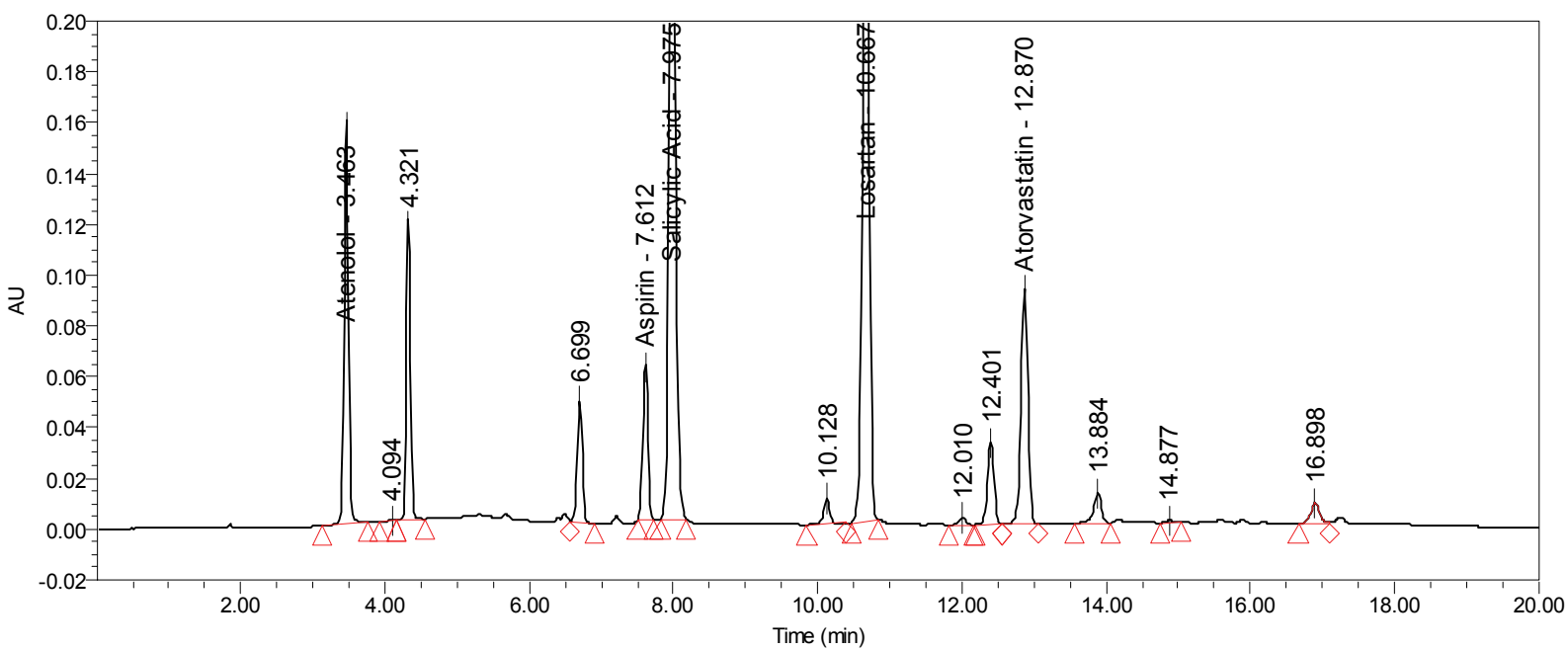

(f)

Figure 3. (a) Acid Degradation sample 0.1N HCl (1h, $\left.100^{\circ} \mathrm{C}\right)$; (b) Base Degradation sample: 0.1N NaOH (2h, Reflux); (c) Peroxide Dégradation sample: 5\% Peroxide (48h, RT); (d) Photo stability degradation; (e) Thermal degradation: $60^{\circ} \mathrm{C}$ for $8 \mathrm{~h}$; (f) Accelerated $40^{\circ} \mathrm{C} / 75 \% \mathrm{RH}$ degradation. 
Table 6. Batch analysis for starpill drug product.

\begin{tabular}{ccccc}
\hline $\begin{array}{c}\text { Batch } \\
\text { No: }\end{array}$ & $\begin{array}{c}\text { ATL } \\
\text { (\%assay) }\end{array}$ & $\begin{array}{c}\text { ASP } \\
\text { (\%assay) }\end{array}$ & $\begin{array}{c}\text { LST } \\
\text { (\%assay) }\end{array}$ & $\begin{array}{c}\text { ATV } \\
\text { (\%assay) }\end{array}$ \\
\hline STP/002 & 99.7 & 99.8 & 100.2 & 99.6 \\
STP/005 & 99.6 & 100.3 & 99.4 & 99.8 \\
STP/011 & 100.1 & 99.9 & 99.7 & 100.3 \\
\hline
\end{tabular}

\subsection{Application of the Method to Stability Study}

Accelerated conditions stability studies are performed to establish the stability indicating nature of the method. Accelerated conditions (temperature $40 \pm 2^{\circ} \mathrm{C}$, relative humidity $75 \pm 5 \%$ ) stored sample of the four drug combinations were analyzed by use of the developed LC method for period of 3 month both initially and after intervals of 1,2 , and 3 , months .The results obtained clearly indicates that the method is able to separate all the drug-drug interaction impurities or any other degradation impurities formed during the storage conditions., indicating the method was stability-indicating and highly suitable for drug stability studies and for monitoring the quality of the Polypill.

\subsection{Conclusions}

The single gradient RP-LC method developed for simultaneous quantitative assay of ASP, ATV, ATL and LST in Polypill is precise, accurate and specific. The method was completely validated showing satisfactory data for all the method validation parameters tested. The developed method is stability indicating and can be used for the routine analysis of production samples and also to check the stability of Polypill tablets.

\section{Acknowledgements}

The authors wish to thank the management of United States Pharmacopeia laboratory-India for supporting this work.

\section{References}

[1] N. J. Wald and M. R. Law, "A Strategy to Reduce Cardiovascular Disease by More Than 80 Percent," British Medical Journal, Vol. 326, No. 7404, 2003, p. 1419.

[2] G. Sanz and V. Fuster, "Fixed-Dose Combination Therapy and Secondary Cardiovascular Prevention: Rationale, Selection of Drugs and Target Population," Nature Clinical Practice Cardiovascular Medicine, Vol. 6, No. 2, 2009, pp. 101-110.

[3] S. Yusuf, P. Pais, R. Afzal, et al., "Effects of a Polypill (Polycap) on Risk Factors in Middle-Aged Individuals without Cardiovascular Disease (TIPS): A Phase II, Double-Blind, Randomised Trial," Lancet, Vol. 373, No. 9672, 2009, pp. 341-351.
[4] M. R. Law and N. J. Wald, "Risk factor thresholds: their existence under scrutiny," British Medical Journal, Vol. 324, No. 7353, 2002, pp. 570-576.

[5] V. Kumar, R. P. Shah and S. Singh, "LC and LC-MS Methods for the Investigation of Polypills for the Treatment of Cardiovascular Diseases: Part.1Separation of Active Compo," Journal of Pharmaceutical and Biomedical Analysis, Vol. 47, 2008, pp. 508-515.

[6] V. Kumar, S. Malik and S. Singh, "Polypill for the treatment of cardiovascular diseases: Part 2. LC-MS/TOF characterization of interaction/degradation products of atenolol/lisinopril," Journal of Pharmaceutical and Biomedical Analysis, Vol. 48, No. 3, 2008, pp. 619-628.

[7] M. C. Koester, "An Overview of the Physiology and Pharmacology of Aspirin and Nonsteroidal Anti-Inflammatory Drugs," Journal of Athletic Training, Vol. 28, No. 3, 1993, pp. 252-254, 256-259.

[8] S. P. Clissold, "Aspirin and Related Derivatives of Salicylic Acid," Drugs, Vol. 32, Supplement 4, 1986, pp. 826.

[9] R. G. Bakker-Arkema, M. H. Davidson, R. J. Goldstein, "Efficacy and Safety of a New HMG-CoA Reductase Inhibitor, Atorvastatin, in Patients with Hypertriglyceridemia," Journal of the American Medical Association, Vol. 275, No. 2, 1996, pp. 128-133.

[10] A. N. Wadworth, D. Murdoch, R. N. Brogden, "Atenolol: A Reappraisal of its Pharmacological Properties and Therapeutic Use in Cardiovascular Disorders," Drugs, Vol. 42, No. 3, 1991, pp. 468-510.

[11] B. M. Psaty, T. D. Koepsell, J. P. LoGerfo, et al., "B-Blockers and Primary Prevention of Coronary Heart Disease in Patients with High Blood Pressure," Journal of the American Medical Association, Vol. 261, No. 14, 1989, pp. 2087-2094.

[12] K. L. Goa and A. J. Wag, "Losartan Potassium: A Review of its Pharmacology, Clinical Efficacy and Tolerability in the Management of Hypertension," Drugs, Vol. 51, No. 5, 1996, pp. 820-845.

[13] E. R. Montgomery, S. Taylor, J. Segretario, et al., "Development and Validation of a Reversed-Phase Liquid Chromatographic Method for Analysis of Aspirin and Warfarin in a Combination Tablet Formulation," Journal of Pharmaceutical and Biomedical Analysis, Vol. 15, No. 1, 1996, pp. 73-82.

[14] D. G. Sankar, M. S. M. Raju, K. Sumanth and P. V. M. Latha, "Asian HPLC Method for Estimation of Atorvastatin in Pure and Pharmaceutical Dosage Form," Journal of Chemistry, Vol. 17, 2005, pp. 2571-2574.

[15] S. Erturk, A. E. Sevinc, L. Ersoy and S. Ficicioglu, "HPLC Method for the Determination of Atorvastatin and its Impurities in Bulk Drug and Tablets," Journal of Pharmaceutical and Biomedical Analysis, Vol. 33, 2003, pp. 1017-1023.

[16] A. Puratchikody, R. Valarmathy, P. Shiju, "RP-HPLC Determination of Atorvastatin Calcium in Solid Dosage Forms," Journal of Pharmaceutical Reviews, 2003, pp. 79-80. 
[17] B. Stanisz and L. Kania, "Validation of HPLC Method for Determination of Atorvastatin in Tablets and for Monitoring in Solid Phase," Acta Poloniae Pharmaceutica, Vol. 63, No. 6, 2006, pp. 471-476.

[18] G. Bahrami, B. Mohammadi, S. Mirzaeei and A. Kiani, "Determination of Atorvastatin in Human Serum by Reverse Phase High Performance Liquid Chromatography with UV Detection," Journal of Chromatography B: Analytical Technologies in the Biomedical and Life Sciences, Vol. 826, 2005, pp. 41-45.

[19] M. Jemal, Z. Ouyang, B. C. Chen and D. Teitz, "Quantitation of Atorvastatin and its Bio-Transformation Products in Human Serum by HPLC with Electro Spray Tandem Mass Spectrometry," Rapid Communications in Mass Spectrometry, Vol. 13, 1999, pp. 1003-1015.

[20] M. Hermann, H. Christensen and J. L. Reubsaet, "Determination of Atorvastatin and Metabolites in Human Plasma with Solid Phase Extraction Followed by LCTandem MS," Analytical and Bioanalytical Chemistry, Vol. 382, No. 5, 2005, pp. 1242-1249.

[21] S. R. Dhaneshwar, S. Yadav, A. Mhaske and S. Kadam, "HPTLC Method for Determination of Content Uniformity of Atorvastatin Calcium Tablets," Indian Journal of Pharmaceutical Sciences, Vol. 67, 2005, pp. 182-186.

[22] C. V. N. Prasad, C. Parihar, K. Sunil and P. Parimoo, "Simultaneous Determination of Amiloride, Hydrochlorothiazide and Atenolol in Combined Formulation by Derivative Spectroscopy," Journal of Pharmaceutical and Biomedical Analysis, Vol. 17, 1998, pp. 877-884.

[23] S. M. Al-Ghannam, "A Simple Spectrophotometric Method for the Determination of B-Blockers in Dosage Forms," Journal of Pharmaceutical and Biomedical Analysis, Vol. 40, No. 1, 2006, pp. 151-156.
[24] A. P. Agrekar and S. G. Powar, "Reverse Phase High Performance Liquid Chromatographic Determination of Ramipril and Amlodipine in Tablets," Journal of Pharmaceutical and Biomedical Analysis, Vol. 21, 2000, pp. 1137-1142.

[25] M. B. Shankar, F. A. Metha, K. K. Bhatt, R. S. Metha and M. Geetha, "Simultaneous Spectrophotometric Determination of Losartan Potassium and Hydrochlorothiazide in Tablets," Indian Journal of Pharmaceutical Sciences, Vol. 65, No. 2, 2003, pp. 167-170.

[26] C. F. Pedroso, J. G. de Oliveira, F. R. Campos, et al., "A Validated RP-LC Method for Simultaneous Determination of Losartan Potassium and Amlodipine Besilate in Pharmaceutical Preparations," Chromatography, Vol. 69, Supplement 2, pp. 201-206.

[27] D. D. Rao, N. V. Satyanarayana, S. S. Sait, Y. R. Reddy and K. Mukkanti, "Simultaneous Determination of Losartan Potassium, Atenolol and Hydrochlorothiazide in Pharmaceutical Preparations by Stability-Indicating UPLC," Chromatography, Vol. 70, No. 4, 2009, pp. 647-651.

[28] "ICH Stability Testing of New Drug Substances and Products Q1A (R2)," International Conference on Harmonization, IFPMA, Geneva, 2003.

[29] "ICH guidelines on Validation of Analytical procedures, Text and Methodology Q2 $\left(\mathrm{R}_{1}\right)$," FDA, Published in the Federal Register 60, 1995.

[30] "United States Pharmacopoeia," 32nd Edition, United States Pharmacopeial Convention, Rockville, 2009.

[31] M. Bakshi and S. Singh, "Development of Validated Stability-Indicating Assay Methods-Critical Review," Journal of Pharmaceutical and Biomedical Analysis, Vol. 28, No. 6, 2002, pp. 1011-1040. 